\title{
FORWARD-LOOKING MODEL DEDICATED TO THE STUDY OF ELECTRIC VEHICLE RANGE CONSIDERING DRIVE CYCLES
}

\author{
Khaled Atamnia ${ }^{1}$, Abdesselam Lebaroud ${ }^{1}$, Saikat Adikari ${ }^{2}$ \\ ${ }^{1}$ National Polytechnic School of Constantine, Algeria \\ ${ }^{2}$ India Institute of Technology Kharagpur (IIT), India \\ E-Mail1:atamnia.khaled.inh@gmail.com, \\ khaled.atamnia@enp-constantine.dz \\ E-Mail²:saikatadikari@iitkgp.in
}

\begin{abstract}
This paper deals with the forward-looking model of an electric vehicle (EV). Various simulation tests have been conducted to investigate the effects of the environmental conditions and powertrain design on the $E V$ driving range. The simulation results show the importance of the forward modeling approach in selecting the EV components such as the battery capacity, the power and torque limits of the electric motor, and the impact of this selection on the $E V$ performance during different driving cycles. The simulation results manifest that the forward model is useful when scaling the battery pack to determine the maximum capacity and selecting the suitable motor power and its size. The characteristics of the General Motor EV1 model have been selected in this study to verify the proposed approach.
\end{abstract}

Keywords: Electric vehicle, Forward-looking model, Backwards-looking model, Model based design, Electric vehicle range, EV powertrain, Hardware-in-the-loop testing, Drive cycle.

\section{INTRODUCTION}

The limited range remains a central issue when it comes to commercialization of electric vehicles [1]. This limitation leads to range anxiety, which describes the drivers stress regarding the available battery range while driving an electric vehicle. Consider this issue as a barrier against the general acceptance of electric vehicle [2]. Energy consumption and vehicle range of EV are affected by varying climate conditions, not only resulted on direct influence on the operation of the electric components, but also the increase in the accessory power consumption due to cabin heating, ventilating, and air-conditioning [3] which causes draining of high power from the battery. The energy consumption also depends on other factors such as the vehicle weight, driving style, and terrain conditions [3]. Modelling and simulation are necessary for automotive designers to decide the best energy control strategy, suitable components size [4], and to study the reasons of range limitation.

Electric vehicle behaviour mathematically described based on the fundamental principles of physics. But the use of equation-based modeling tools like MATLAB/Simulink is of great value when it comes to studying the energy flow, performance, and the efficiency of EV. It might be helpful in the analysis of the impact of several parameters, and driving scenarios on vehicle range. Researchers have adopted many approaches to model the electric vehicle system, such as backwards and forward-looking approaches [5]-[6], or a a combination of both approaches. These models typically used for components sizing [6] or acceleration performance estimation [5]. Simulation tools, more specifically forwardlooking models which target specific vehicles, are widely used in the industry to address the component interactions that affect fuel consumption and performance [15]. In this paper, the forward-looking approach adopted to evaluate the vehicle performance and environmental conditions, which may have a direct or indirect impact on vehicle range. The model is useful in the design requirement which represents the first step in the V-Cycle as shown in Figure 1.

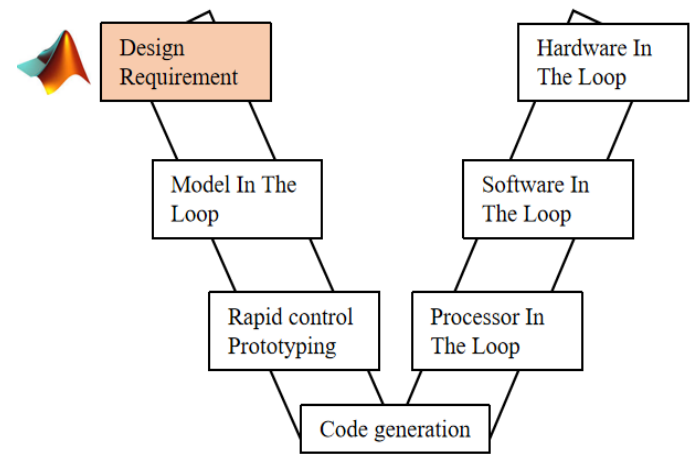

Figure 1. V-cycle model

Furthermore, it provides a better understanding of vehicle dynamics, motor and battery limits. This model could be used to co-simulate battery-pack with the motor and drivetrain to impose its constraints on achievable performance [7]. The model helps the designer to investigate the suitability of vehicle components with each other. Also, it contributes to the understanding of the vehicle behaviour, through the performance analysis of the EV under a set of conditions such as high or low temperature, terrain condition and the driving styles.

\subsection{Forward facing approach for vehicle modeling}

The Forward approach also called the engine-to-wheel or rear-to-front method. It uses a driver model that tries to follow the desired speed profile [5]. Forward-looking models feature a driver model, and it gives insight to the drive-ability of the electric car. The forward-looking model provides a better understanding of the dynamics and physical limits of the power train. Also, it makes control 
development and implementation on Hardware-In-theLoop (HIL) systems easier [6]. Furthermore, this concept can realize a stage of interfacing between simulation and real-time control. The main drawback of this process is the simulation time which could be relatively long in some cases (such as consideration of high dynamics) [8] compared to backwards-looking model [6]. Because of the quasi-steady nature of this approach, the controller cannot be developed. Consequently, this will ignore the transient effects.

Figure. 2 described the application of forward-looking approach to model an electric vehicle system.

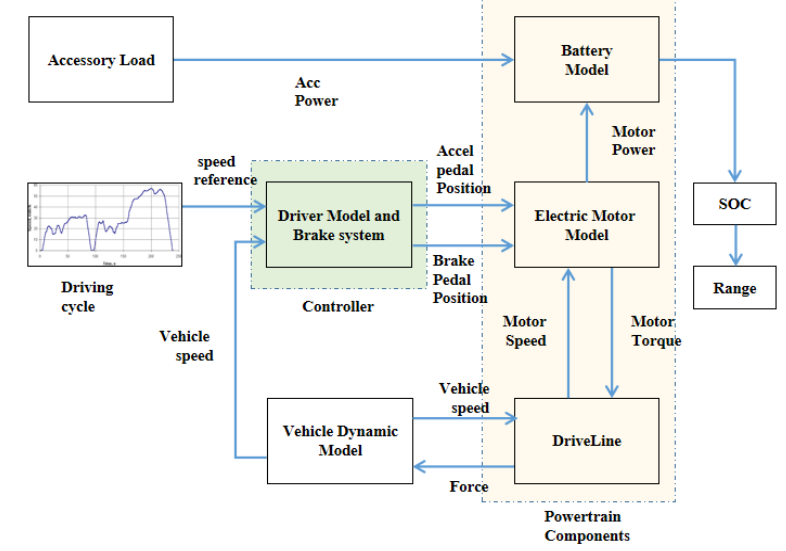

Figure 2. Forward looking model

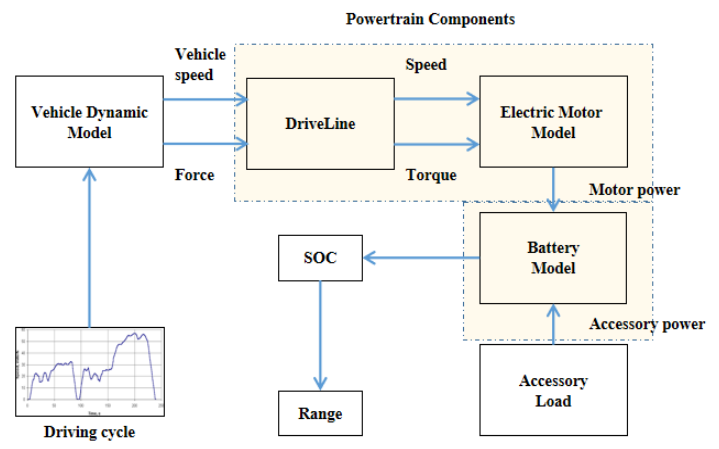

Figure 3. Backward-looking model

\section{Ideal vehicle dynamic model}

Since the land vehicles designed to move primarily in one direction, only single dimensional lateral dynamics considered [9]. There are five lateral force components: inertial force, longitudinal traction force, air drag, tire rolling resistance, and gravity when the vehicle [9] as shown in Figure 4.

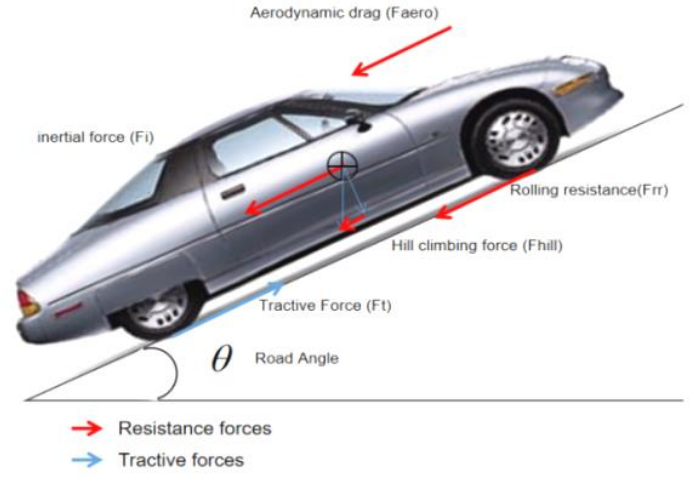

Figure 4. Longitudinal model

\subsection{Rolling resistance Force}

Rolling resistance is the force that resists vehicle movement on a surface. This force approximately constant and it depends on vehicle speed. Where $\mathrm{C}_{\mathrm{rr}}$ is a rolling resistance coefficient, its typical value starts from 0.015 down to about 0.005 for electric vehicle tires [10].

$$
F_{r r}=C_{r r} m g \cos (\theta)
$$

Where $g$ is acceleration of gravity and $m$ is vehicle weight.

\subsection{Aerodynamic drag}

The aerodynamic drag force caused by the friction of the vehicle body moving through the air, it can be concluded from the equation (2) that force $F_{\text {aero }}$ is a function of vehicle shape and size defined by drag coefficient and weight respectively. Drag coefficient $C_{d}$ typical value is between 0.25 and 0.3 , but some electric vehicle designs have achieved $0.19[10]$

The latter is directly affected by the shape of the vehicle.

$$
F_{\text {aero }}=\frac{1}{2} \rho A C_{d} v^{2}
$$

Where $\rho$ is the density of the air and $1.25 \mathrm{~kg} / \mathrm{m}^{3}$ is a reasonable value to use in most cases [10], $A$ is the frontal area, $v$ is the vehicle velocity.

\subsection{Hill climbing force}

Grade force $\left(\mathrm{F}_{\text {hill }}\right)$ or hill climbing, sometimes called gravitational force is the required force to drive a vehicle uphill, and it is proportional to vehicle mass and grade angle.

$$
F_{\text {hill }}=m g \sin (\theta)
$$

\subsection{Inertial force}

If the velocity of the vehicle $v$ is changing, then clearly a force $\mathrm{F}_{i}$ is needed in addition to previous forces. This force will provide the linear acceleration $a$ of the vehicle, and is given by well-known equation derived by Newton's second law [10].

$$
F_{i}=m_{i} a
$$


Where $m_{i}$ is the inertial vehicle weight.

\subsection{Tractive effort}

Tractive effort is a total traction force, or a sum of all the previous resistive forces (inertial force $\left(F_{i}\right)$, Hill climbing force $\left(F_{\text {hill }}\right)$, Aerodynamic drag $\left(F_{\text {aero }}\right)$ and Rolling resistance force $\left(F_{r r}\right)$ ) which required to move a vehicle forward or backwards.

$$
F_{t}=F_{i}+F_{\text {hill }}+F_{\text {aero }}+F_{r r}
$$

In the case of a forward model, the forces acting on the vehicle are summed and then divided by the effective mass of the vehicle, giving an estimate of the vehicle's acceleration which is then integrated to find velocity and displacement [8] (see equation 6).

$$
\frac{d v}{d t}=\frac{\left(F_{t}-F_{\text {hill }}-F_{\text {aero }}-F_{r r}\right)}{m_{i}}
$$

\subsection{Motor model}

$$
P_{\text {motor }}=T_{\text {motor }} \times w_{\text {motor }}
$$

Where $P_{\text {motor }}$ is motor power, $T_{\text {motor }}$ and $w_{\text {motor }}$ are speed and motor torque respectively.

$$
P_{\text {motor_loss }}=k_{c} T^{2}+k_{i} w+k_{w} w^{3}+C
$$

The equation 8 is a good approximation of the power loss for all types of motor [10], Where $k_{c}, k_{i}, k_{w}$ are copper, Iron, and wind age losses respectively for electric motor as shown in Table 1.

Table 1. Typical parameters values of induction motor[10].

\begin{tabular}{|l|l|}
\hline Parameter & $100 \mathrm{~kW}$, high-speed induction motor \\
\hline$k_{c}$ & 0.3 \\
\hline$k_{i}$ & 0.01 \\
\hline$k_{w}$ & $5.0 \times 10^{-6}$ \\
\hline$C$ & 600 \\
\hline
\end{tabular}

$$
\text { Copper }_{\text {Loss }}=k_{c} T^{2}
$$

The rate of change of magnetic flux is directly proportional to the speed of the rotor to how quickly it is turning. We can thus say that [10]:

$$
\text { Iron }_{\text {loss }}=k_{i} w
$$

The iron loss is proportional to the frequency in which the magnet field changes, the higher the frequency changes, the higher hysteresis losses and greater eddy currents. $k_{i}$ value gives a good indication of iron losses, even it will be affected by the magnet field strength, among other non-constant factors. $k_{i}$ is constant depends on the way the magnet field is provided, by excitation or permanent magnet which is more constant in the second case [10].

$$
\text { Windage }_{\text {power }}=k_{w} w^{3}
$$

Where $C$ is a constant used to designate these losses [10].

$$
P_{\text {motor_input }}=T_{\text {motor }} w_{\text {motor }}+P_{\text {motor_loss }}
$$

When the efficiency of motor can be calculated as shown by equation (13) based on [10], when the motor and its controller and inverter were abstracted together.

$$
n_{\text {motor }}=\frac{T_{\text {motor }} w_{\text {motor }}}{T_{\text {motor }} w_{\text {motor }}+k_{c} T_{\text {motor }}^{2}+k_{i} w+k_{w} w^{3}+C}
$$

\subsection{Motor torque and vehicle speed}

To understand the induction motor behaviour during motoring and generating modes, the motor torque has been plotted in function of vehicle speed during US06 drive cycle (see figure 5) as shown in Figure 6, when it depicted the constant torque and constant power regions of the motor.

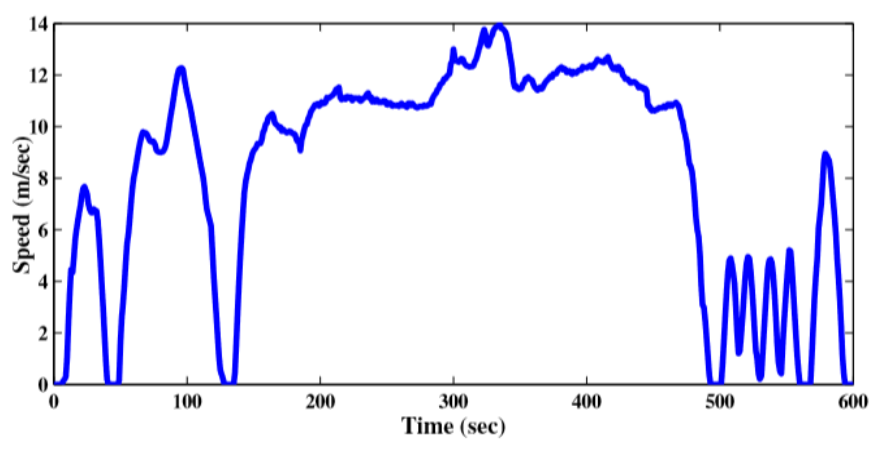

Figure 5. US06 Drive cycle.

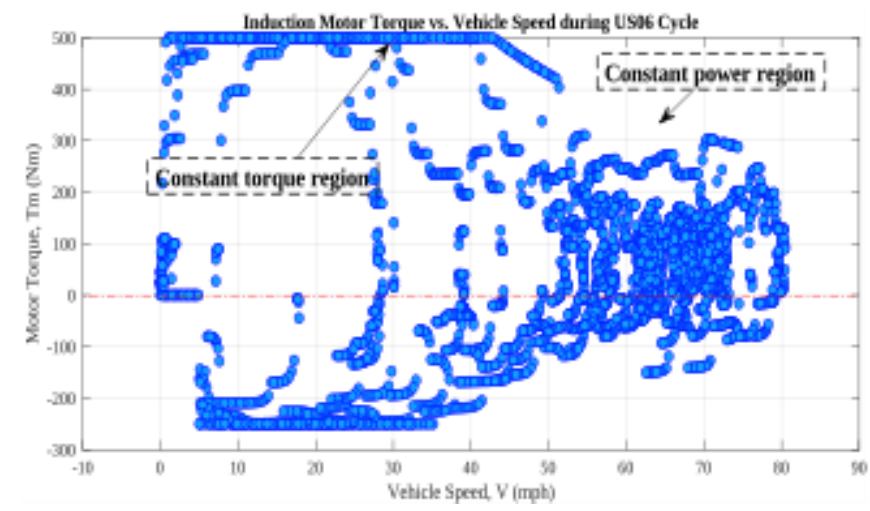

Figure 6. Motor torque vs vehicle speed.

\subsection{Battery model}

A simple battery equivalent circuit has been adopted here to model a battery behavior. Current $\mathrm{I}_{\text {Battery }}$ flows through the internal resistance $R_{\text {Internal }}$ of the battery causes the loss of some of its energy $\mathrm{P}_{\text {loss. }}$ It generates heat known as Joul heating.

$$
P_{\text {loss }}=R_{\text {internal }} \cdot I_{\text {battery }}^{2}
$$




\subsection{State of charge}

State of the charge (SOC) is the equivalent of fuel gauge of the conventional vehicle and is defined as the amount of energy available in a battery at a specific point in time expressed in percentage, and it can be defined by the following formula [16].

$$
S O C=S O C_{\text {init }}+\frac{1}{3600} \int \frac{I_{\text {battery }}}{C_{b}}
$$

where $C_{b}$ is the battery capacity, and $I_{b a t t e r y}$ is battery current.

\subsection{Drive-line model}

Drive-line is a part of vehicle power train which transmit the torque from the motor to the vehicle dynamic model [11]. Where $T_{\text {loss }}$ represents the constant torque loss that associated to drive-line, and $F_{B}$ is the braking force, which has to be subtracted to get a net tractive force that will be sent to vehicle dynamic model. Where $G$ is vehicle gear ratio, and $r_{w}$ is wheel radius.

$$
F_{t}=\left(T_{\text {motor }}-T_{\text {Loss }}\right) \cdot \frac{G}{r_{w}}-F_{B}
$$

\subsection{Range formula}

We can update the vehicle range $V_{\text {range }}$ by considering the capacity available in the battery, and how much used in a single drive cycle, as well as the total distance that the vehicle drove during that drive profile [12]. The $S O C_{\text {min_rated }}$ and $S O C_{\text {max } \_ \text {rated }}$ values represent the allowable battery capacity limits, and $S O C_{\text {start }}$ and $S O C_{\text {end }}$ designate the battery capacity in the beginning, and at the end of the drive cycle profile. However, there are many ways to estimate the vehicle range more accurately.

$$
V_{\text {range }}=\text { DriveCycle }_{\text {distance }} \frac{S O C_{\text {max_rated }_{-}-S O C_{\text {min_rated }_{\text {rate }}}}}{S O C_{\text {start }}-S O C_{\text {end }}}
$$

\subsection{Driver model}

The driver model can be either a PI or a predictive type controller. It receives a drive cycle speed profile as a reference, then it delivers accelerator and brake commands to the control system. The acceleration and brake pedal position is converted to torque command to propel or to brake the vehicle.

\subsection{Drive Cycle}

A driving cycle is a standardized driving pattern designed to test the motor efficiency of the vehicle or the drive-trains. The driving cycle is a speed-time profile which stands for stop/go trips, or relatively smooth highway cycles [9]. The types of drive cycles [14] used to evaluate the performance of the vehicle are presented as follows:

High acceleration aggressive driving cycle (US06).
Urban Dynamo-meter Driving Schedule (UDDS).

High Way Fuel Economy Test (HWFET).

Supplement to FTP-75 with use of air conditioning (SC03).

Federal Test Procedure (FTP72).

New York City Composite Cycle (NYCC).

\section{Results and discussions}

\subsection{Effects of vehicle parameters selection}

In this section, we conducted a series of simulation-based testing for the main components of the General Motors (GM) EV1 model [10] such as the electric motor and the battery. To understand how its size and design could impact the performance of the EV during various driving scenarios.

\subsection{Battery capacity selection}

Battery size influences the maximum torque of the electric motor, vehicle range, and its weight. As we can see from Figure 5, decreasing the battery capacity and keeping the same motor power at $102 \mathrm{kw}$ will reduce the vehicle range by $33 \%$ for battery capacity equal to $40 \mathrm{kwh}$, and by up to $60 \%$ for $24 \mathrm{kwh}$ of capacity. Another useful information that we can conclude from this comparison is: the vehicle range not only depends on the battery sizing but also on driving style. For US06, UDDS, WHFET, SC03, FTP72 the results are almost equal, but it is not the case in NYCC. The vehicle range and battery efficiency for NYCC are considerably lower than other scenarios. In conclusion, selecting the right size of a battery pack will extend the electric vehicle range.

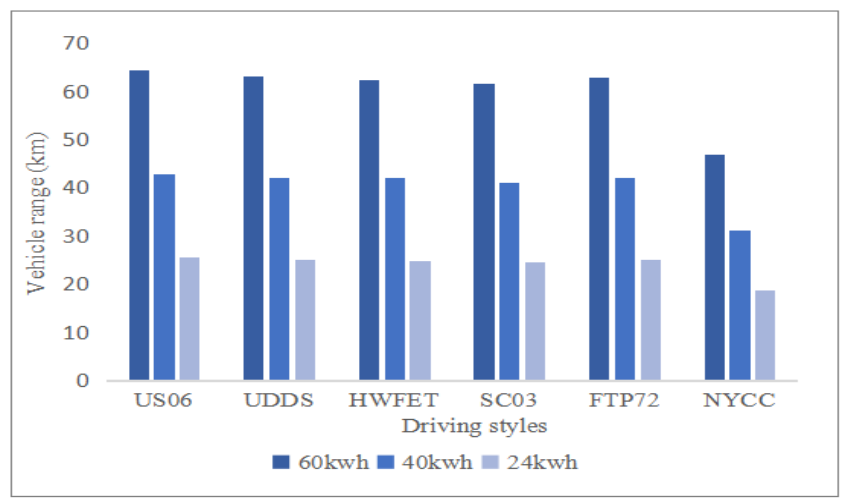

Figure 7. Vehicle range for different battery capacity.

\subsection{Wheel radius selection}

Wheel size not only affects vehicle range, but also has an impact on vehicle acceleration. So it is possible to increase the vehicle driving range by changing wheel size, and these changes are also depend on the drive cycle. As we can see from figure 6 that changing wheel radius from $0.2 \mathrm{~m}$ to $0.4 \mathrm{~m}$ increased the vehicle range by $25 \%$ for HWFET, US06 and by $33 \%$ to $38 \%$ for NYCC, UDDS, FTP72, SC03. 


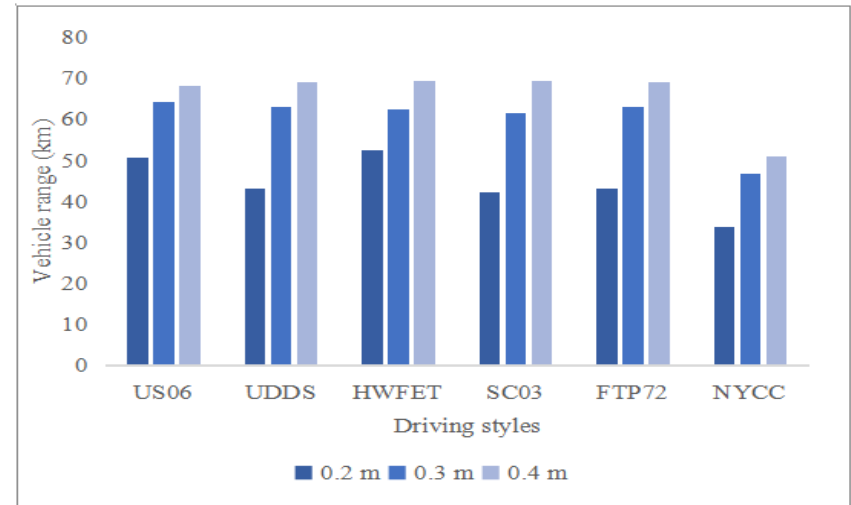

Figure 8. Vehicle range results for different wheel radius.

\subsection{Motor power and torque limits}

The designer has to consider the motor power selection in the early vehicle design phases. The higher motor power we select, the higher the tractive power we get, especially for high-speed driving styles like UDDS and US06 profiles. On the contrary to stop/go driving cycles, where motor efficiency shows the lower values.

On the other hand, vehicle range slightly declined when motor power is increased from $80 \mathrm{kw}$ to $150 \mathrm{kw}$ (Figure .7), expect for NYCC that not affected by these changes. Changing Motor torque from $140 \mathrm{Nm}$ to $500 \mathrm{Nm}$ (see Figure .8) decreased the vehicle range by $10 \%$ and $25 \%$ for US06 and HWFET respectively, and by $67 \%$ up to $87 \%$ for $\mathrm{SC} 03$, UDDS, FTP72, NYCC respectively. The selected battery power in this test seems to be not suitable for the motor, and it has to be smaller in this case. Motor sizing depends on many factors, such as the driving cycle and the correct battery selection to respond to motor power demand.

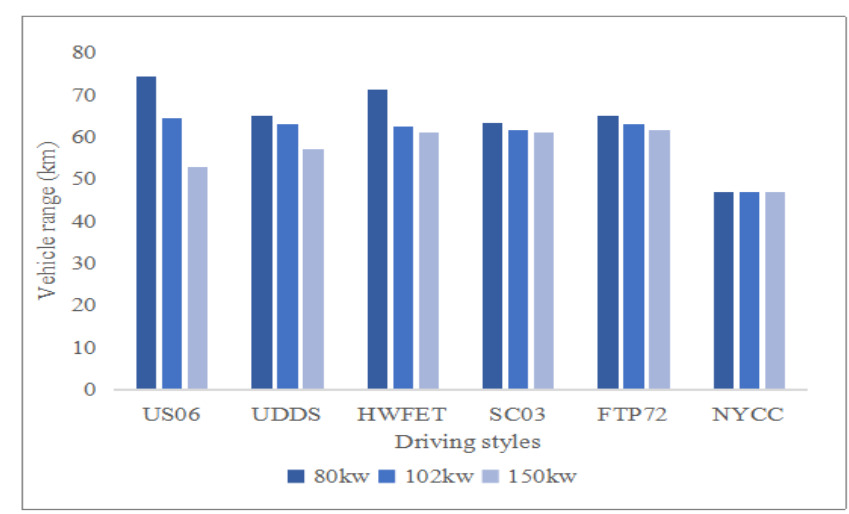

Figure 9. Vehicle range results for different motor power.

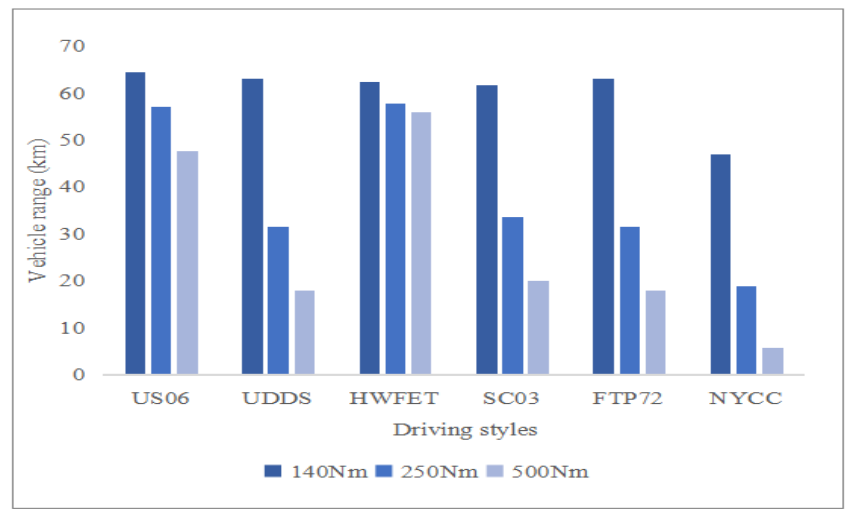

Figure 10. Vehicle range results for different motor torque

\subsection{Gear ratio selection}

Usually, the EVs only have a single gear ratio. In Figure 9 many tests have been conducted for different driving scenarios and gears to investigate the impact of gear ratio selection on vehicle performance. The vehicle designer chooses an optimal gear ratio for the right combination of acceleration, speed, and driving range. Decreasing gear ratio from 11:1 to $3: 1$ has increased vehicle range by up to $50 \%$ for highway driving styles like HWFET and US06. However, this selection will not provide a necessary tractive power to overcome road resistance (see Figure .10). Another effect that worth mentioning here is the acceleration that declined by $70 \%$ for all driving styles.

It is possible to investigate more parameters such as the vehicle weight which has a big impact on the vehicle range. As a result, a simplified vehicle model based on MATLAB/Simulink could be useful to understand some requirement issues such as the gear ratio selection.

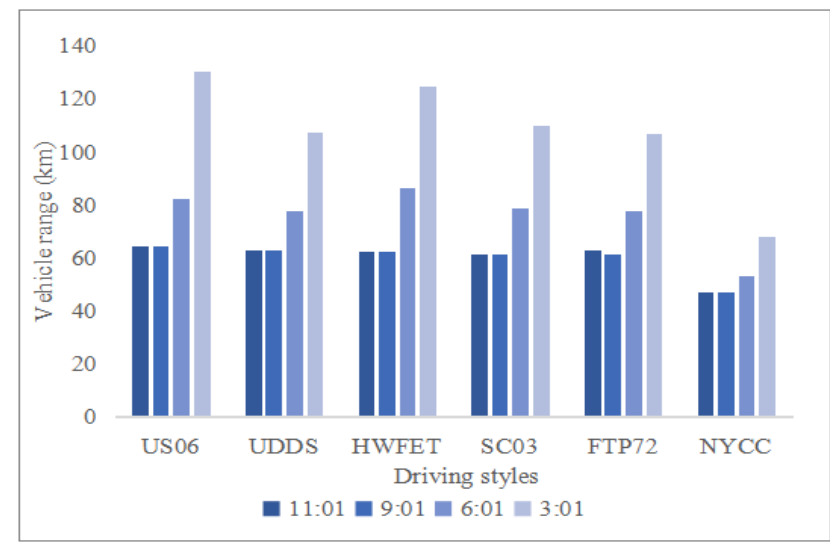

Figure 11. Vehicle range results for different gear ratios. 


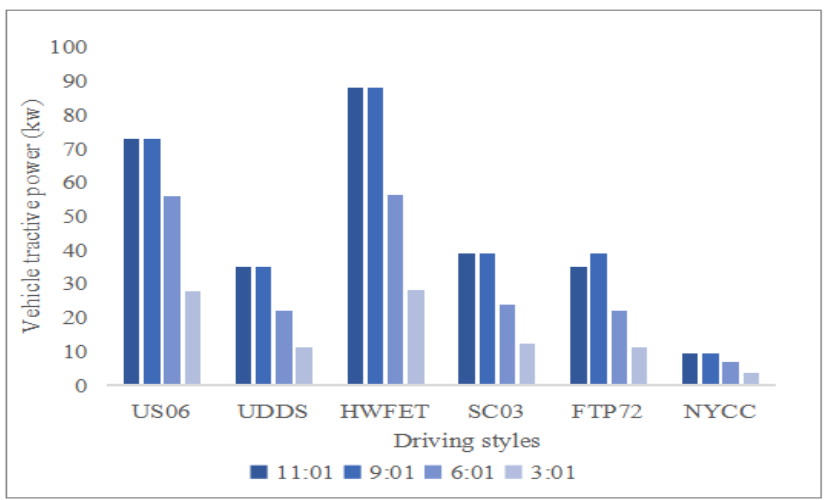

Figure 12. Vehicle tractive power results for different driving style and gear ratio selection.

\subsection{Environmental changes}

It is possible to conclude the effect of temperature on the car by changing the battery internal resistance by a certain percentage. The same thing might be possible for terrain condition where we can change the rolling resistance parameter to emulate its impacts on vehicle range.

\subsection{Terrain conditions}

It is possible to investigate the impact of a traffic situation on vehicle range, and its performance based on the created model and the information in Table 2 . The simulation results in Figure 11 show the lower the rolling resistance, the higher the efficiency. Traffic or road situation is another factor which has an impact on vehicle performance. Increasing rolling resistance from 0.0048 (low resistance tubeless tires) to 0.4 (car tires on loose sand) has affected vehicle range by $43-46 \%$ for all driving scenarios. We can see that from the results of the hard road, the vehicle needs a high tractive power to overcome the resistance showed by that road, and this supposed to drain a high amount of energy from the battery.

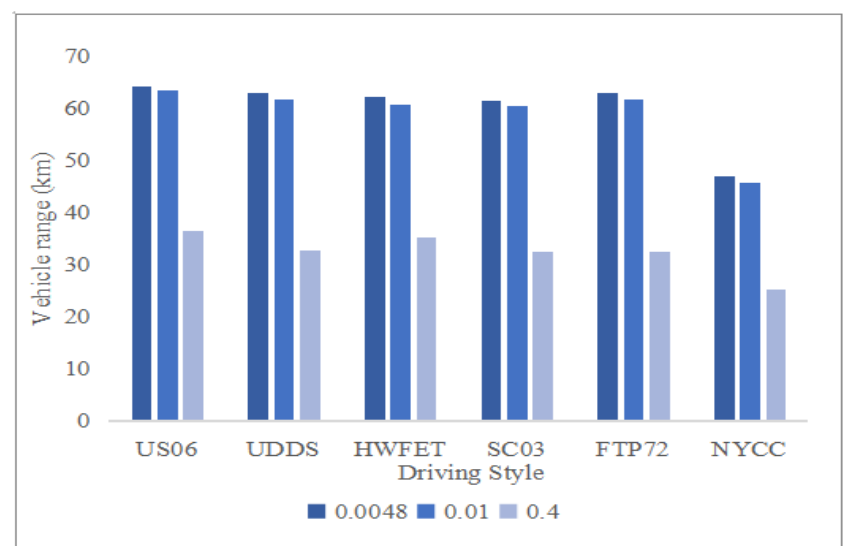

Figure 13. Vehicle range simulation for different road situation.
Table 2: Rolling resistance coefficient for real world roads [13]

\begin{tabular}{|c|c|}
\hline $\begin{array}{c}\text { Rolling resistance } \\
\text { coefficient }\end{array}$ & Real-world roads \\
\hline $0.002-0.005$ & low resistance tubeless tires \\
\hline $0.006-0.01$ & truck tire on asphalt \\
\hline $0.01-0.015$ & $\begin{array}{c}\text { ordinary car tires on concrete, } \\
\text { new asphalt, cobbles small } \\
\text { new }\end{array}$ \\
\hline 0.02 & car tires on tar or asphalt \\
\hline 0.02 & $\begin{array}{c}\text { car tires on gravel - rolled } \\
\text { new }\end{array}$ \\
\hline 0.03 & $\begin{array}{c}\text { car tires on cobbles - large } \\
\text { worn }\end{array}$ \\
\hline $0.04-0.08$ & $\begin{array}{l}\text { car tire on solid sand, gravel } \\
\text { loose worn, soil medium hard }\end{array}$ \\
\hline $0.2-0.4$ & Car tire on loose sand \\
\hline
\end{tabular}

\subsection{Cold and hot weather}

The vehicle simulated under different weather conditions based on the relationship between temperature and internal resistance of the battery when heat lowers it, and cold raises it. The cold weather decreases vehicle range by $10 \%$ to $12 \%$, as shown in Figure 12 and Figure 13, especially for high speed driving styles, and this effect diminished for low-speed scenarios like NYCC. On the other hand, driving a vehicle in the low-speed region increased the vehicle efficiency.

On the contrary to the high-speed profiles when we notice the drop of motor efficiency. However, hot weather affected vehicle range positively for low-speed driving styles, and negatively for high-speed scenarios. So it is not easy to conclude a general rule about the effects of climate changes on vehicle performance, the driver's style, and accessory loads such as the air conditioner and heater.

\section{Conclusion}

In this paper it was found that through the adoption of forward-looking approaches, many factors may contribute significantly to raising the overall performance of the vehicle, such as the driving style, the selection of the battery capacity, the motor power and torque limits. Since the model built by adopting the forward-looking approach, it is possible to use it for the selection of the powertrain configuration as well as control algorithm validation for hardware-in-the-loop (HIL), rapid control prototyping ( $\mathrm{RCP}$ ), or component-in-the-loop (CIL) testing.

The backwards-looking is quasi-steady model, which ignore the transient effects. Consequently, it cannot be used for the development of control system or adopted for HIL testing. The forward-looking model is useful when scaling the battery pack to determine the maximum capacity and motor power demand. Also, deciding the power electronic converter by investigating the peak current of this pack. The designer does not have to be concerned about the type of the battery, electric motor, or even the controller. Motor and inverter efficiency were abstracted. In the end, the main goal is to understand the vehicle behavior and to be able to improve its performance, or even choose the appropriate control algorithm. 


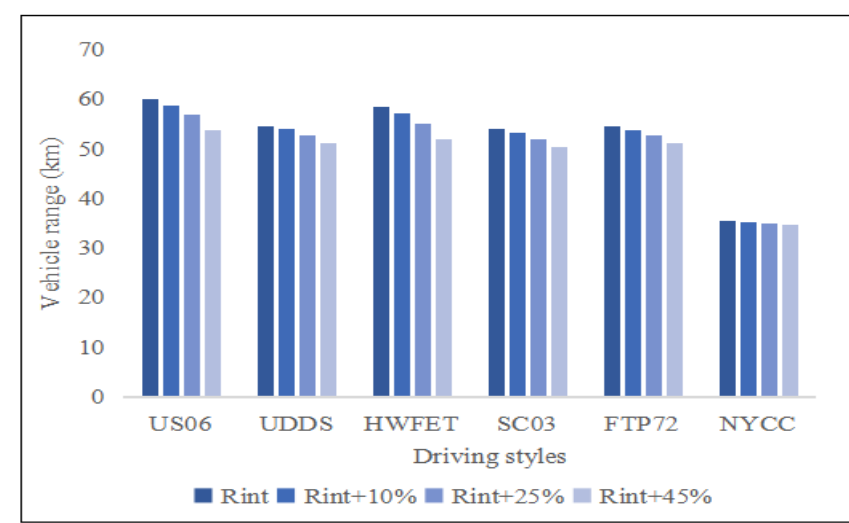

Figure 14. vehicle range simulation for cold weather.

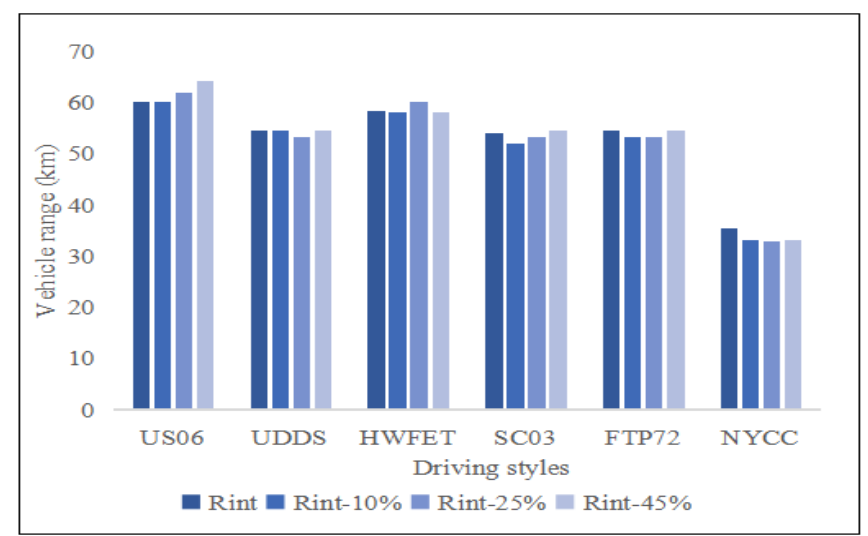

Figure 15. Vehicle range simulation for hot weather.

\section{REFERENCES}

[1] Enthaler, A. and Gauterin, F., 2013, December. Significance of internal battery resistance on the remaining range estimation of electric vehicles. In 2013 International Conference on Connected Vehicles and Expo (ICCVE) (pp. 94-99). IEEE.

[2] Salah, K. and Kama, N., 2017. Inter-service providercharging protocol: a solution to address range anxiety of electric vehicle owners. Energy Procedia, 136, pp.157-162.

[3] Iora, P. and Tribioli, L., 2019. Effect of ambient temperature on electric vehicles' energy consumption and range: model definition and sensitivity analysis based on nissan leaf data. World Electric Vehicle Journal, 10(1), p.2.

[4] Laurikko, J., Granström, R. and Haakana, A., 2012. Assessing range and performance of electric vehicles in Nordic driving conditions-Project" RekkEVidde". World Electric Vehicle Journal, 5(1), pp.45-50.

[5] Mohd, T.A.T., Hassan, M.K. and Aziz, W.M.K.A., 2015. Mathematical modeling and simulation of an electric vehicle. Journal of Mechanical Engineering and Sciences, 8(1), pp.1312-1321

[6] Mohan, G., Assadian, F. and Longo, S., 2013. Comparative analysis of forward-facing models vs backwardfacing models in powertrain component sizing.

[7] Dixon, G., Stobart, R. and Steffen, T., 2015. Unified backwards facing and forwards facing simulation of a hybrid electric vehicle using MATLAB Simscape (No. 2015-011215). SAE Technical Paper.
[8] Mohan, G., Assadian, F. and Longo, S., 2013 Comparison between Forward and Backward approaches for the simulation of an Electric Vehicle

[9] Nam, K.H., 2018. AC motor control and electrical vehicle applications. CRC press.

[10] Larminie, J. and Lowry, J., 2012. Electric vehicletechnologyexplained. John Wiley \& Sons.

[11] MathWorks Student Competitions Team (2021). MATLAB and Simulink Racing Lounge: Vehicle Modeling (https://www.mathworks.com/matlabcentral/filee xchange/63823-matlab-and-Simulink-racing-loungevehicle-modeling), MATLAB Central File Exchange. Retrieved April 4, 2021.

[12] Plett, G.L., 2015. Battery management systems, Volume II: Equivalent-circuit methods (Vol. 2). Artech House.

[13] Engineering ToolBox, (2008). Rolling Resistance. A vailableat: https://www.engineeringtoolbox.com/rollingfriction-resistance-d_1303.html (Accessed 15 May. 2020).

[14] Barlow, T.J., Latham, S., McCrae, I.S. and Boulter, P.G., 2009. A reference book of driving cycles for use in the measurement of road vehicle emissions. TRL Published Project Report.

[15] Autonomie software. https://www.autonomie.net

[16] Hegazy, O. and Van Mierlo, J., 2012. Optimal power management and powertrain components sizing of fuel cell/battery hybrid electric vehicles based on particle swarm optimisation. International journal of vehicle design, 58(2-4), pp.200-22. 
Appendix:Characteristics of GM-EV1.

Table 3. Characteristics of GM-EV1 [10].

\begin{tabular}{|l|l|}
\hline Electric motor & Three-phase induction motor $102 \mathrm{~kW}$ \\
\hline Transmission & Single-speed reduction integrated with motor and differential \\
\hline Battery & lead acid $18.7 \mathrm{kWh}$ \\
\hline Range & $170-100$ miles $(112-160 \mathrm{~km})$ \\
\hline Wheelbase $(\mathrm{mm})$ & 2512 \\
\hline Length $(\mathrm{mm})$ & 4310 \\
\hline Width $(\mathrm{mm})$ & 1765 \\
\hline Height $(\mathrm{mm})$ & 1283 \\
\hline Curb weight $(\mathrm{kg})$ & 1400 \\
\hline
\end{tabular}

